\title{
Effects of Relative Positioning of Energy Sources on Weld Integrity for Hybrid Laser Arc Welding
}

\author{
Shuangyu Liu ${ }^{\mathrm{a}}$, Yanqing Li ${ }^{\mathrm{a}, 1}$, Fengde Liu ${ }^{\mathrm{a}}$, Hong Zhang ${ }^{\mathrm{a}}$, Hongtao Ding ${ }^{\mathrm{b}}$
}

a College of Mechanical and Electrical Engineering, Changchun University of Science and Technology, 7089 Weixing Rd., Changchun 130022, P.R. China

${ }^{\mathrm{b}}$ Department of Mechanical \& Industrial Engineering, University of Iowa, Iowa City, IA 52242, USA

\begin{abstract}
This study is concerned with the effects of laser and arc arrangement on weld integrity for the hybrid laser arc welding processes. Experiments were conducted for a high-strength steel using a 4kW Nd: YAG laser and a metal active gas (MAG) welding facility under two configurations of arc-laser hybrid welding (ALHW) and laser-arc hybrid welding (LAHW). Metallographic analysis and mechanical testing were performed to evaluate the weld integrity in terms of weld bead geometry, microstructure and mechanical properties. The morphology of the weld bead cross-section was studied and the typical macrostructure of the weld beads appeared to be cone-shaped and cocktail cup-shaped under ALHW and LAHW configurations, respectively. The weld integrity attributes of microstructure, phase constituents and microhardness were analyzed for different weld regions. The tensile and impact tests were performed and fracture surface morphology was analyzed by scanning electron microscope. The study showed that ALHW produced joints with a better weld shape and a more uniform microstructure of lath martensite, while LAHW weld had a heterogeneous structure of lath martensite and austenite.
\end{abstract}

Keywords: Hybrid laser arc welding; Weld Integrity; Microstructure; Mechanical properties; High-strength steel

${ }^{1}$ Corresponding author email: liyanqing@ @ust.edu.cn Tel:+86-431-8558 2207; Fax: +86-431-8538 4427 


\section{Introduction}

The hybrid laser arc welding process combines the highly focused intensity of a laser with the joint filling capability of gas metal arc welding (GMAW). The process usually results in a very narrow heat-affected zone (HAZ) with deep penetration and high travel speeds relative to traditional processes. It provides a unique opportunity for thicker welds with less filler metal or higher travel speeds than typical welding, and hence has been widely implemented in various industrial applications from shipbuilding to automobile production.

The positioning arrangement of the two heat sources in the welding direction plays a critical role in the hybrid laser arc welding process. There are two basic configurations, namely, the laser-leading hybrid process with the laser beam preceding the arc [1-3] and the arc-leading hybrid process with the arc preceding the laser beam [4-8]. Extensive research has been done to investigate these hybrid welding processes. To optimize the process stability, weld profile and weld penetration, research work in [5-7] studied the effects of welding parameters such as distance between laser beam and arc $\left(D_{L A}\right)$, focused position of laser beam, arc voltage and welding current, laser power, shielding gas composition and the shielding gas flow. Spatters can be generated on the surface of the weld if the parameters are not appropriately chosen. Li et al. [9] investigated the coupling of a Nd:YAG laser beam and a metal inert gas (MIG) arc with the spectrum of the plasma. Their results showed that the laser-MIG hybrid welding processes caused the plasma energy to focus on the center of the welding arc and plasma has stronger radiation intensity near the welding pool. Zhou and Tsai [10] developed mathematical formulas and a numerical solution to investigate the complicated transport phenomena during the spot hybrid laser-MIG welding process. They found that weld pool dynamics, cooling rate, and final weld bead geometry were strongly affected by the impingement process of the droplets. Gao et al. [11] proposed a mathematical model by coupling the laser beam and arc functions into the plasma width and simulated the weld pool development and dynamic process in stationary laser-MIG hybrid welding. They evaluated the transient weld pool shape and complicated liquid metal velocity distribution from two kinds of weld pools to a unified weld pool.

Research has been done to understand the interactions of the two heat sources with different energy distributions during the laser-arc hybrid welding process. Kah et al. [12] studied how the 
relative positioning of the different sources in laser-arc hybrid welding affected the overall weld quality and penetration depth. Their analysis was based on research results of various studies carried out by different research groups. Casalino et al. [13] investigated arc leading versus laser leading during the hybrid welding of aluminum alloy. Their results showed that the laser-leading configuration produced a better penetration and sounder weld. The laser-leading configuration was found to be more convenient with respect to the arc leading one. For the arc-leading a lower penetration was found to require speed slowdown for deeper penetration. Cao et al. [14] investigated hybrid laser arc welding of thick section high strength low alloy steel. Their results showed that the laser-leading hybrid welding process can produce higher quality welds due to less underfill and porosity defects than arc-leading welding. Wang et al. [15] investigated the effect of the welding direction on the plasma and metal transfer behavior of hybrid welding processes. They found that the temperature and electron density distribution exhibited a bimodal behavior in the case of arc-leading mode, which did not exist in the case of laser-leading mode. They found that the arc-leading mode led to a longer time to generate a drop, while the laser-leading mode reduced the required voltage for the same current.

From the above discussion, it is obvious that the strong coupling effect between laser beam and arc affected the weld thermal cycle and the flow of molten pool of hybrid welding thus the microstructure and the mechanical properties of weld joint. Nonetheless, the effects of the relative positioning of laser beam with arc on the microstructure and mechanical properties during laser-arc hybrid welding were rarely studied in literature according to the authors' best knowledge.

In this work, two configurations of arc-laser hybrid welding process (ALHW) and laser-arc hybrid welding process (LAHW) are experimentally investigated. The effects of the relative positioning of laser beam with arc on the weld bead geometry, microstructure and mechanical properties of weld joints are experimentally analyzed in details for hybrid laser-arc welding.

\section{Experiments}

\subsection{Hybrid Welding Experiments}

The base material used in the welding experiments was a low alloy high-strength steel (HSS), which was cut into $400 \times 100 \times 6.6 \mathrm{~mm}$ coupons. The filler wire was made of an austenitic stainless steel 
(ASS) with $1.2 \mathrm{~mm}$ in diameter. The compositions of the base metal and the filler wires were determined by an ARL 4460 Metals Analyzer as shown in Table 1. Before welding, the specimens were chemically cleaned with acetone to eliminate any surface contamination. These hybrid welding experiments were conducted to obtain a full penetration of $6.6 \mathrm{~mm}$ thick HSS specimens for a butt weld configuration with a Y-groove preparation. The weld specimen geometry is schematically described in Fig. 1.

Fig. 2 shows the experimental system for the hybrid welding experiments, which used a $4 \mathrm{~kW}$ Nd:YAG laser (Model HL4006D by TRUMPF) in conjunction with a power supply (Model YD-350A G2HGE by Panasonic). The laser operated in the continuous wave (CW) mode with a wavelength of $1.06 \mu \mathrm{m}$. During the experiments, the laser beam was focused to a spot of $0.5 \mathrm{~mm}$ in diameter on the top surface of the specimen by a fixed focus lens with a focal length of $220 \mathrm{~mm}$. The shielding gas for the arc torch comprised of carbon dioxide (5\%) and argon (95\%) was delivered at a flow rate of $16 \mathrm{~L} / \mathrm{min}$. The welding experimental parameters are given in Table 2. Two experimental configurations of arc-leading ALHW and laser-leading LAHW processes, as illustrated in Fig. 3, were investigated in this study to evaluate the relative positioning of energy sources on the weld integrity.

\subsection{Metallographic Analysis and Mechanical Testing}

To carry out the metallographic analysis, the weld specimens were firstly sectioned and polished with suitable abrasives and a diamond paste. The specimens were then etched with a $10 \%$ oxalic acid to reveal the fusion zone and increase the contrast from the base metal. The microstructure of the weld bead was analyzed using an optical microscope (OM) and a scanning electron microscope (SEM, Model JEOL JSM-6510 LA). In order to detect various phase constituents present in the weld fusion zones, a micro-zone X-ray diffraction (XRD) analysis was carried out at different locations of the welds. The X-ray diffractometer (Model Rigaku Ultimate 3) used the $\mathrm{Cu}$ Ka radiation with a wavelength of $1.544 \AA$.

The tensile test specimens were prepared according to the ASTM E8 standard. The tensile tests were carried out using a 25-ton universal testing machine at room temperature. The impact test specimens were prepared to $10 \times 5 \times 55 \mathrm{~mm}$ in dimension with a V-notch of $1.6 \mathrm{~mm}$ in width and $2 \mathrm{~mm}$ 
in depth, as schematically described in Fig. 1. The Charpy impact tests were carried out according to the ASTM E23 standard at $-40{ }^{\circ} \mathrm{C}$. Vickers hardness was measured perpendicular to the weld using a load of $200 \mathrm{~g}$ with a loading duration of 15 seconds.

\section{Results and Discussions}

\subsection{Macrostructure of Welds}

The morphology of the weld bead cross-section was compared for the two experimental configurations of ALHW and LAHW. The typical macrostructure of the weld beads appeared to be cone-shaped and cocktail cup-shaped by the ALHW and LAHW configurations, respectively, as can be seen in Fig. 4. Under both conditions, the weld bead was consisted of an arc zone, a laser fusion zone, and a transition zone between laser and arc zones. The effect of experimental configuration of laser beam and electric arc were examined in terms of the width of the arc zone and the penetration depth of the laser zone. During the ALHW process, as can be observed in Fig. 5 (a), the laser beam aimed at the inclined surface of weld pool, which was pushed by the arc force and impinging momentum of droplets. When the laser beam aimed at the inclined surface with the highest level of liquid phase, the molten metal material in the weld pool had a tendency to flow downward along the laser-induced keyhole wall. It was observed that these fluid-phase materials rotate in the same direction, which helped the molten metal flow toward the bottom of weld pool $[5,10]$. Therefore, the morphology of the weld bead cross-section resulted in cone-shaped under the ALHW condition, as can be seen in Fig. 4 (a).

During the LAHW process, the laser beam aimed at the front edge of the electric arc. It is likely that at the bottom of the laser zone only a small part of the base metal melted but was not remelted by GMAW, as can be seen in Fig. 4 (b). Meanwhile, melted metal from the tip of the wire arrived in the melt zone just in front of the edge of laser-induced keyhole, which is shown in Fig.5 (b). Subsequently, the molten metal flew downward along the keyhole wall to join the base material, which resulted in a large amount of wire composition in the laser zone. Under the LAHW condition, the cross section morphology of the weld bead resulted in "cocktail cup" shaped, which is shown in Fig.4 (b). 


\subsection{Microstructure of Welds}

Fig. 6 shows the solidification structures in the fusion zone by ALHW, which correspond to the regions denoted as $A, B$ and $C$ shown in Fig. 4a. From Figs. 6 (a) and (c), it can be seen that the grain structure in the laser zone is finer than that in the arc zone. The solidification structure of the arc zone was consisted of long columnar dendrites perpendicularly grown from the molten pool wall towards the center. The dendritic grain structure showed well-developed primary arms in the center region of the weld bead. The growth direction of long columnar dendrite coincidently aligned well with the <100> orientation, as shown in Fig. 6 (d). The distance between the dendrites ranged from $12 \mu \mathrm{m}$ to $18 \mu \mathrm{m}$. The solidification structure of the laser zone was composed of fine dendrites and columnar dendrites, which were finer than those in the arc zone. The solidification structure of the transition zone was found to evolve from columnar dendrites to dendrites as can be seen in Fig. 6 (b). Figs. 7 (a)-(c) further examine the microstructures in the fusion zone by the ALHW process. The microstructure of the arc zone and the transition zone were composed of a great amount of lath martensite, which were characterized with a high hardness ranging from $404 \mathrm{HV}$ to $480 \mathrm{HV}$. The microstructure of the laser zone was composed of a great amount of lath martensite with some retained austenite.

Fig. 8 shows the solidification structure of the fusion zone by LAHW, which correspond to the regions denoted as $A, B$ and $C$ in Fig. 4b. Comparing the grain structure in Fig. 8(a) with that shown in 8(c), it is clearly that the grains in the arc zone are coarser than those in the laser zone. The solidification structure of the arc zone was composed of short and coarse dendrites in a layered columnar structure. Equiaxed grains can be observed in the center of the laser zone. Columnar crystals and coarse dendrites can be observed densely distributed from the center towards to boundary of the laser zone, which were finer than those in the laser zone by the ALHW process. An apparent transition can be observed in the solidification structures of the transition zone for LAHW, as shown in Fig. 8(b). Fig. 8(d) shows the micrograph of the transition zone at a higher magnification, which shows a short dendritic structure with well developed primary arms and clearly distinguishable short and coarse secondary arms. Figs. 9 (a)-(c) show the microstructural micrographs of the fusion zone, which have a heterogeneous structure of lath martensite and austenite. The microstructure of the arc zone was composed of a great amount of lath martensite, which were characterized by a high hardness ranging from $420 \mathrm{HV}$ to $480 \mathrm{HV}$. The 
microstructure of the laser zone was composed of austenite and lath martensite, which were characterized by a much lower hardness ranging from $190 \mathrm{HV}$ to $370 \mathrm{HV}$ approximately.

The LAHW weld microstructure was investigated for its chemical composition profile using energy dispersive x-ray spectroscopy analysis (EDS) for the region shown in Fig. 10 (a). Fig.10 (b) shows the measured chemical concentrations (wt.\%) of ferrite-promoting elements (Cr) and austenite-promoting elements $(\mathrm{Ni}, \mathrm{Mn})$ across the weld. The laser zone contained a higher percentage of $\mathrm{Cr}$, Ni and $\mathrm{Mn}$ than those in the arc zone, which corroborated well with the presence of more austenite in the laser zone. The austenite-stabilizing elements such as Ni and Mn distributed in the darker phase of primary dendrites, while the ferrite-promoting elements such as $\mathrm{Cr}$ and $\mathrm{Si}$ dispersed in the lighter inter-dendritic phases. In comparison, the distribution of $\mathrm{Ni}$ and $\mathrm{Cr}$ elements in the ALHW welded seam was more uniform as shown in Fig. 11, which agreed well with the uniform distribution of hardness.

The solidification structure under different heat source arrangements is dominated by the solidification process physics and can be determined by the weld pool parameters such as grain growth rate $(\mathrm{R})$, temperature gradient $(\mathrm{G})$, and cooling rate $(\dot{T})$. Fig. 12 shows the evolution maps of weld solidification structure as a function of these three parameters [16]. The hybrid welding speed V, is related to grain growth rate $(\mathrm{R})$ according to the formula:

$$
\begin{aligned}
& \mathrm{R}=\mathrm{V} \cdot \cos (\theta) \\
& \dot{\mathrm{T}}=\mathrm{G} \cdot \mathrm{R}
\end{aligned}
$$

Where $\theta$ is the angle between the welding direction and the normal of isothermal surface in the welding molten pool. Fig. 12 shows the growth rate $\mathrm{R}$ reaches its minimum and maximum at the fusion boundary and centerline, respectively. Conversely, the temperature gradient is the highest and lowest at the fusion boundary and centerline, respectively. As a result, the temperature gradient to growth ratio $(\mathrm{G} / \mathrm{R})$ decreases from the fusion boundary line to the centerline of the weld bead, which causes the solidification mode from columnar dendritic to dendritic for ALHW (Fig. 6) or columnar to equiaxed dendritic for LAHW (Fig. 8) across the fusion zone. For the ALHW process, the laser beam aimed at the inclined surface of the molten pool, and the molten pool was fully penetrated with a laser-induced keyhole. The keyhole was filled by the plasma plume of the high-temperature ionizing metal vapor, 
which had the highest temperature in the plume core remains for about $15,000-19,000 \mathrm{~K}$ for the iron-argon system [17]. The temperature of the molten pool wall maintained a constant of $1774 \mathrm{~K}$, the melting point of iron. During the quasi-steady welding process, the temperature along the keyhole axis direction was assumed to be uniformly distributed, while a high temperature gradient was considered along the radial direction. In comparison, high temperature gradients were generated at the edge of the laser keyhole during the LAHW process. The temperature gradient decreased due to the formation of arc molten pool with relatively lower temperatures.

The temperature gradient of the weld bead under different arrangements can be investigated with the grain size of HAZ. Grain coarsening in HAZ can be explained by the process thermal cycle. As shown in Fig. 13, the HAZ grain size by LAHW was significantly larger than that of ALHW. The grain growth close to the fusion line for LAHW is caused by the high HAZ temperature during the LAHW process, which was most likely much higher than of the ALHW process. Under the same welding operation parameters, the cooling rate $(\dot{\mathrm{T}})$ of the LAHW process was less than that of the ALHW process, which meant that the time of being melted for LAHW process was longer than that of the ALHW process. Therefore the secondary dendrites became coarse through the consumption of small dendrite arm during cooling, as can be seen in Fig. 8 (d).

The weld bead was examined for phase identification by micro-zone X-ray diffraction (XRD), as presented in Fig. 14. The XRD pattern indicated that the weld bead was mainly consisted of martensite and austenite. Other possible phases such as delta ferrite and carbides of intermetallic were not detected by the X-ray diffraction patterns, which indicated completely austenitic solidification mode. Among all the diffraction patterns, the diffraction peak of M ( $\left.\begin{array}{lll}1 & 1 & 0\end{array}\right)$ had the highest intensity and more phases, while the diffraction peaks of M (2 $\left.\begin{array}{lll}0 & 0\end{array}\right)$ and $\mathrm{M}\left(\begin{array}{lll}2 & 1 & 1\end{array}\right)$ in the entire weld bead had the lowest intensity and fewer phases. A close comparison between the laser zones of ALHW and LAHW showed that the diffraction peak strength of austenite phase of the LAHW sample was stronger than that of the ALHW sample. The findings in X-ray diffraction profile conformed with the aforementioned microstructures of the weld bead of LAHW. 


\subsection{Mechanical Properties}

The transverse tensile strength of all the weld joints was experimentally evaluated. For each condition, three specimens were tested. The tensile test results of hybrid welding joints are given in Table 3. The average tensile strength of ALHW joint was 1,035 MPa, while that of LAHW joints was $875 \mathrm{MPa}$. The results show that the specimens fractured at the weld seam, which indicated that the strength of the weld metal was lower than that of the base metal.

The fractured surface of tensile specimens was analyzed by SEM. Fig. 15 shows the SEM fractograph macrostructure and microstructure of joints for ALHW. The hybrid joints of ALHW were consisted of uniform dimples, which indicated that the specimen failed in a ductile manner under tensile loading. The difference between the laser zone and the arc zone was the dimple size. The dimple size of the laser zone was smaller than that of the arc zone, as shown in Fig.15 (a1) and (a2). Fig. 16 shows the SEM fractograph macrostructure and microstructure of joints for LAHW. Different fracture mode can be observed for the arc zone and the laser zone. Fig. 16 (b1) shows the fracture surface of the arc zone appears in ductile with partially cleavage fracture, which was alternated with coarse dimples and pure shear fracture. From the coarser dimples size, the tensile strength of LAHW process was found to be lower than that of ALHW process. The fracture surface of laser zone was consisted of uniform, fine dimples.

Table 3 shows low-temperature impact energy of weld metal and base metal. It is clear that the LAHW weld joints exhibited higher impact toughness values than those of the ALHW weld joints. The low-temperature impact absorbed energy of LAHW weld joints was $17 \mathrm{~J}$ at $-40{ }^{\circ} \mathrm{C}$. From the XRD patterns as shown in Fig.14, the peaks of austenitic phases in the LAHW weld joints were the highest. Based on the presence of austenitic phase in the weld metal of LAHW, the toughness of weld metal was higher than the weld metal of ALHW process. The fractured surface of the impact tested fractrograph is shown in Fig.17. Many dimples can be seen in the SEM structure of LAHW weld joints in Fig.17 (b). The dimple size exhibits a directly proportional relationship with ductility, that is, if the dimple size is finer, the ductility of the joint is higher and vice versa [18]. On the other hand, the impact specimen fracture surfaces of ALHW welded joints showed mixed mode fractures, which consisted of many shallow dimples and cleavage fracture. 


\section{Conclusions}

The effects of the arrangement mode of the laser and arc on the microstructure and mechanical properties of weld bead by laser-GMAW hybrid welding were investigated and the results are shown as follows:

1. The cross section morphology of the weld bead was cone-shaped and cocktail cup-shaped for ALHW and LAHW, respectively.

2. The microstructure of ALHW weld was consisted of lath martensite, and was characterized by the high hardness ranging from 404 to $480 \mathrm{HV}$. The microstructure of LAHW weld had the heterogeneous structure of lath martensite and austenite. The microstructure of the arc zone was composed of lath martensite, and was characterized with a high hardness ranging from 420 to 480 HV. The microstructure of laser zone was composed of austenite and lath martensite, and was characterized with a low hardness ranging from 190 to $370 \mathrm{HV}$.

3. The tensile strength of weld joints of ALHW was higher than that of the LAHW. The impact energy of weld joints of ALHW was lower than that of the LAHW.

4. ALHW produced joints with a better weld shape and uniformity microstructure. The temperature gradient at the molten pool of ALHW process was higher. The grain sizes in HAZ of LAHW were significantly greater than that of ALHW.

\section{ACKNOWLEDGEMENTS}

This work was supported by the National Nature Science Foundation Program of China under grant number 51305044. The authors gratefully acknowledge the financial support provided for the part of the study carried out at the University of Iowa by the National Science Foundation under Grant Number EPS-1101284.

\section{REFERENCES}

[1] Shinn BW, Farson DF, Denney PE. Laser stabilisation of arc cathode spots in titanium welding. Sci Technol Weld Join 2005;10:475-81. 
[2] Tusek J, Suban M. Hybrid welding with arc and laser beam. Sci Technol Weld Join 1999;4:308-11.

[3] Gao M, Zeng X, Hu Q. Effects of gas shielding parameters on weld penetration of CO 2 laser-TIG hybrid welding. J Mater Process Technol 2007;184:177-83.

[4] Wu CS, Chen MA, Li SK. Analysis of excited droplet oscillation and detachment in active control of metal transfer. Comput Mater Sci 2004;31:147-54.

[5] Liu S, Liu F, Zhang H, Shi Y. Analysis of droplet transfer mode and forming process of weld bead in CO 2 laser-MAG hybrid welding process. Opt Laser Technol 2012;44:1019-25.

[6] Bang HS, Bang HS, Kim YC, Oh IH. A study on mechanical and microstructure characteristics of the STS304L butt joints using hybrid CO 2 laser-gas metal arc welding. Mater Des 2011;32:2328-33.

[7] Campana G, Fortunato A, Ascari A, Tani G, Tomesani L. The influence of arc transfer mode in hybrid laser-MIG welding. J Mater Process Technol 2007;191:111-3.

[8] Huang R, Liu L, Zhang F. Influences of laser in low power YAG laser-MAG hybrid welding process. Chinese Opt Lett 2008;6:47-50.

[9] Li Z, Wang W, Wang X, Li H. A study of the radiation of a Nd: YAG laser-MIG hybrid plasma. Opt Laser Technol 2010;42:132-40.

[10] Zhou J, Tsai H-L. Modeling of transport phenomena in hybrid laser-MIG keyhole welding. Int J Heat Mass Transf 2008;51:4353-66.

[11] Gao Z, Wu Y, Huang J. Analysis of weld pool dynamic during stationary laser-MIG hybrid welding. Int J Adv Manuf Technol 2009;44:870-9.

[12] Kah P, Salminen A, Martikainen J. The effect of the relative location of laser beam with arc in different hybrid welding processes. Mechanika 2010;3:68-74.

[13] Casalino G, Campanelli SL, Dal Maso U, Ludovico AD. Arc leading versus laser leading in the hybrid welding of aluminium alloy using a fiber laser. Procedia CIRP 2013;12:151-6.

[14] Cao X, Wanjara P, Huang J, Munro C, Nolting A. Hybrid fiber laser-Arc welding of thick section high strength low alloy steel. Mater Des 2011;32:3399-413. 
[15] Zhang W, Hua X, Liao W, Li F, Wang M. The effect of the welding direction on the plasma and metal transfer behavior of $\mathrm{CO}_{2}$ laser+ GMAW-P hybrid welding processes. Opt Lasers Eng 2014;58:102-8.

[16] Kou S. Welding metallurgy. 2nd ed. USA (NJ): John Willey \& Sons Inc., 2002. 143-69.

[17] Mościcki T, Hoffman J, Szymański Z. Modelling of plasma plume induced during laser welding. J Phys D Appl Phys 2006;39:685.

[18] Sathiya P, Mishra MK, Shanmugarajan B. Effect of shielding gases on microstructure and mechanical properties of super austenitic stainless steel by hybrid welding. Mater Des 2012;33:203-12. 


\section{List of TABLES}

Table 1 Chemical compositions of HSS and ASS (wt. \%)

\begin{tabular}{cccccccccccc}
\hline & \multicolumn{10}{c}{ Chemical composition (wt. \%) } \\
\cline { 2 - 11 } & $\mathrm{C}$ & $\mathrm{Cr}$ & $\mathrm{Ni}$ & $\mathrm{Mn}$ & $\mathrm{Mo}$ & $\mathrm{Si}$ & $\mathrm{Cu}$ & $\mathrm{S}$ & $\mathrm{P}$ & $\mathrm{Fe}$ \\
\hline HSS & 0.22 & 0.60 & 0.95 & 1.40 & 0.50 & 0.28 & 0.32 & 0.008 & 0.002 & Bal. \\
ASS & 0.09 & 21.12 & 9.14 & 1.60 & 0.37 & - & - & 0.01 & 0.02 & Bal. \\
\hline
\end{tabular}

Table 2 Welding parameters

\begin{tabular}{|c|c|}
\hline Welding parameters & \\
\hline Welding speed $\mathrm{v}[\mathrm{m} / \mathrm{min}]$ & 0.8 \\
\hline Angle of welding torch $\theta\left[^{\circ}\right]$ & 60 \\
\hline Defocusing amount $\Delta \mathrm{f}[\mathrm{mm}]$ & 0 \\
\hline Extension length $\mathrm{L}[\mathrm{mm}]$ & 13 \\
\hline Laser powder $\mathrm{P}[\mathrm{kW}]$ & 2.5 \\
\hline MAG current I $[\mathrm{A}]$ & 220 \\
\hline MAG voltage $\mathrm{U}[\mathrm{V}]$ & 26 \\
\hline Distance between laser and arc $\mathrm{D}_{\mathrm{LA}}[\mathrm{mm}]$ & 3 \\
\hline
\end{tabular}

Table 3 Tensile and impact test results

\begin{tabular}{|c|c|c|c|c|c|c|c|}
\hline \multirow{3}{*}{$\begin{array}{l}\text { Experiment } \\
\text { No. }\end{array}$} & \multirow{2}{*}{\multicolumn{3}{|c|}{$\begin{array}{l}\text { Ultimate tensile strength } \\
\qquad(\mathrm{MPa})\end{array}$}} & \multirow{3}{*}{$\begin{array}{l}\text { Fracture } \\
\text { location }\end{array}$} & \multirow{2}{*}{\multicolumn{3}{|c|}{$\begin{array}{l}\text { Charpy energy } \\
-40^{\circ} \mathrm{C}(\mathrm{J})\end{array}$}} \\
\hline & & & & & & & \\
\hline & 1 & 2 & 3 & & 1 & 2 & 3 \\
\hline ALHW & 1060 & 1040 & 1004 & Weld bead & 13.5 & 12.8 & 14.5 \\
\hline
\end{tabular}


$\begin{array}{llllllll}\text { LAHW } & 856 & 876 & 894 & \text { Weld bead } & 16.5 & 17.0 & 18.1\end{array}$

HSS

1360

ASS

649

\section{List of FIGURES}

Fig.1 Schematic of groove shape used in this work.

Fig.2 Set-up of Nd:YAG laser-GMAW hybrid welding.

Fig.3 Schematic representation of hybrid welding with leading arc and leading laser arrangement

Fig.4 Macrostructure of the welded joints (a) ALHW and (b) LAHW

Fig.5 High-speed video images of molten surface and laser acted point (a) ALHW and (b) LAHW

Fig.6 Solidification structures of the welded joints for ALHW; (a) arc zone, (b) transition zone and (c) laser zone, (d) columnar dendrite in transition zone at high magnification.

Fig.7 Microstructure of the fusion zone of ALHW; (a) arc zone, (b) transition zone and (c) laser zone

Fig.8 Solidification structures of the welded joints for LAHW; (a) arc zone, (b) transition zone and (c) laser zone, (d) short and coarse dendrite in transition zone at high magnification.

Fig.9 Microstructure of the welded joints for LAHW; (a) arc zone, (b) transition zone and (c) laser zone

Fig.10 Chemical composition of LAHW weld. (a) Micrograph with EDS measurement path; (b)

Elements distribution curves from EDS measurement.

Fig.11 Distribution of Ni and Cr elements in the ALHW welded seam.

Fig.12 Schematic view illustrating the effects of temperature gradient $\mathrm{G}$ and growth rate $\mathrm{R}$ on the morphology of solidification microstructure [14].

Fig.13 The grain size of HAZ for (a) ALHW and (b) LAHW

Fig.14 X-ray diffraction (XRD) analysis result of the weld metal. 
Fig.15 Fracture surface of the welded joints for ALHW

Fig.16 Fracture surface of the welded joints for LAHW

Fig.17 Fracture surface of Charpy V tested specimen: (a) ALHW, (b) LAHW 


\section{Figures}
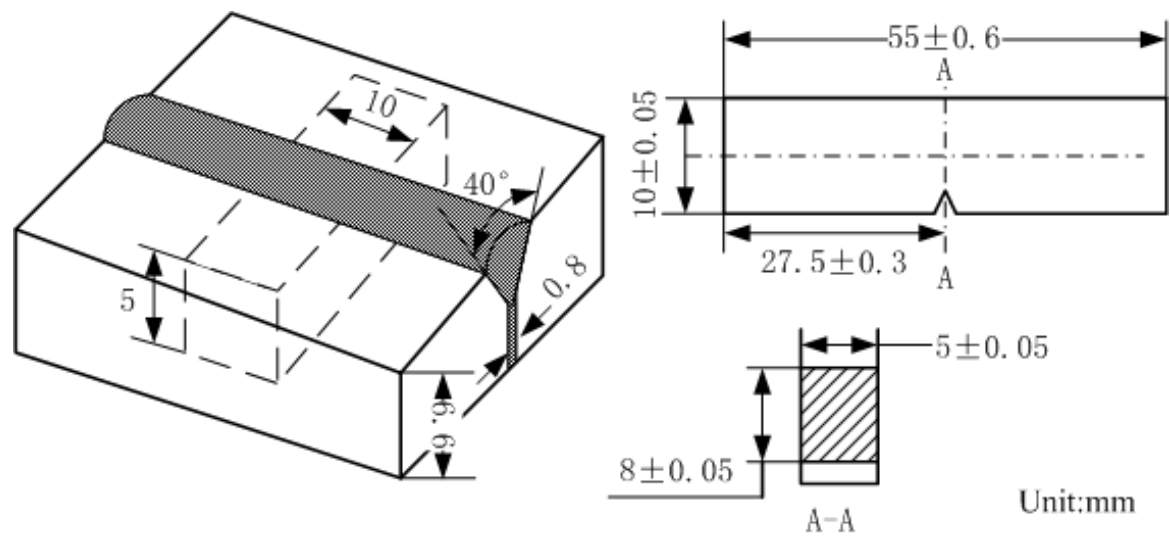

Fig.1 Schematic diagram of groove and impact specimen size.

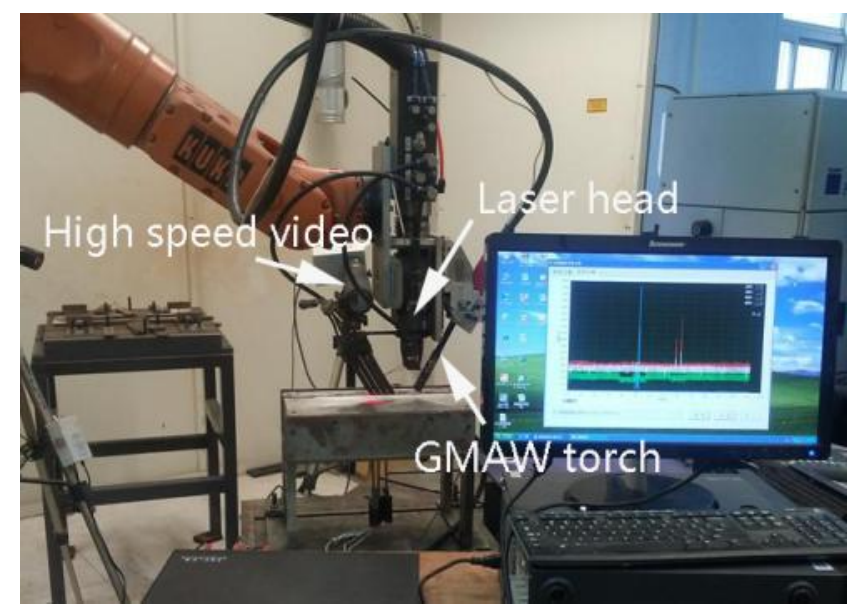

Fig.2 Set-up of Nd:YAG laser-GMAW hybrid welding.

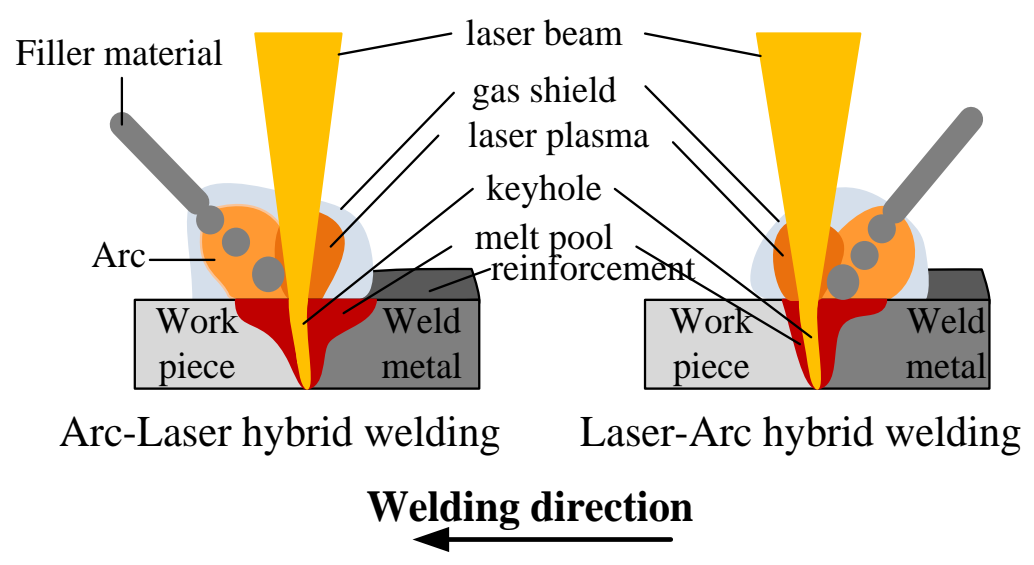


Fig.3 Schematic representation of hybrid welding with leading arc and leading laser arrangement

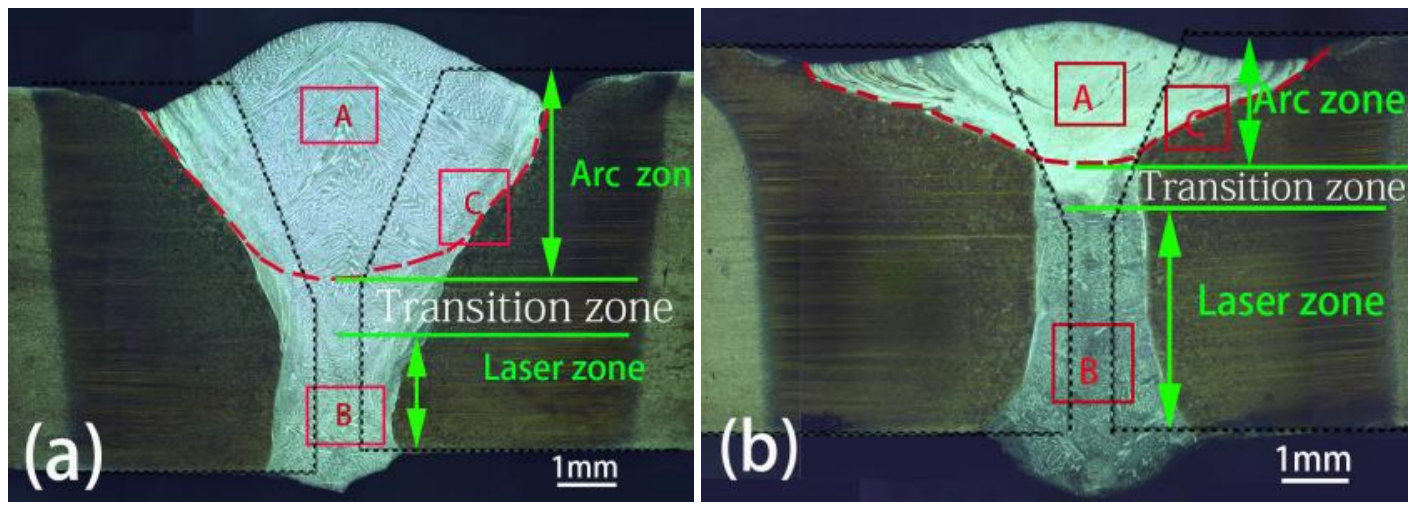

Fig.4 Macrostructure of the welded joints (a) ALHW and (b) LAHW
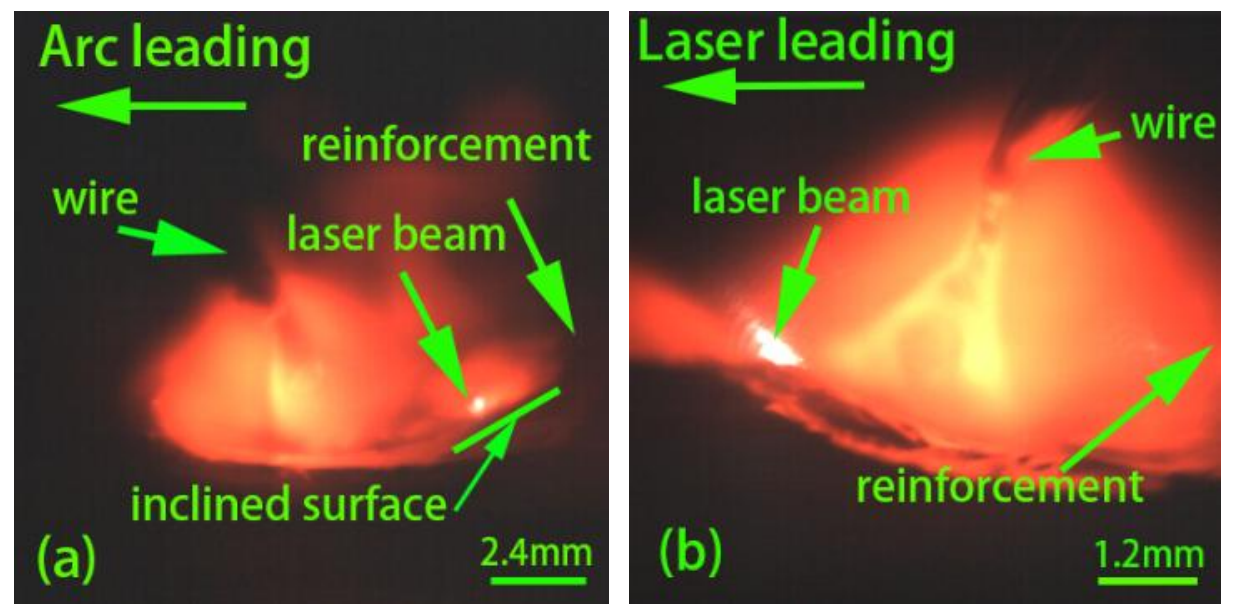

Fig.5 High-speed video images of molten surface and laser acted point (a) ALHW and (b) LAHW 


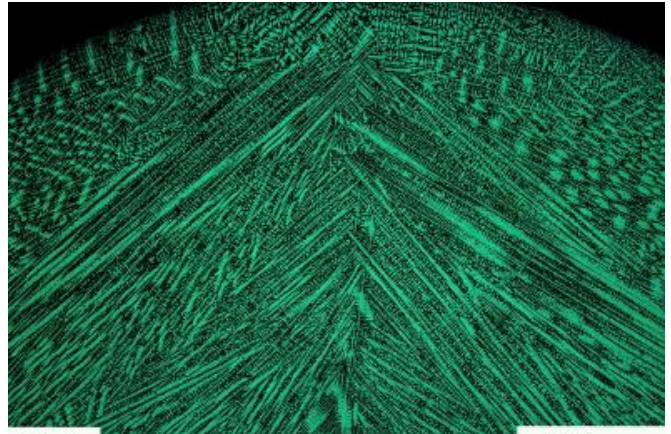

(a)

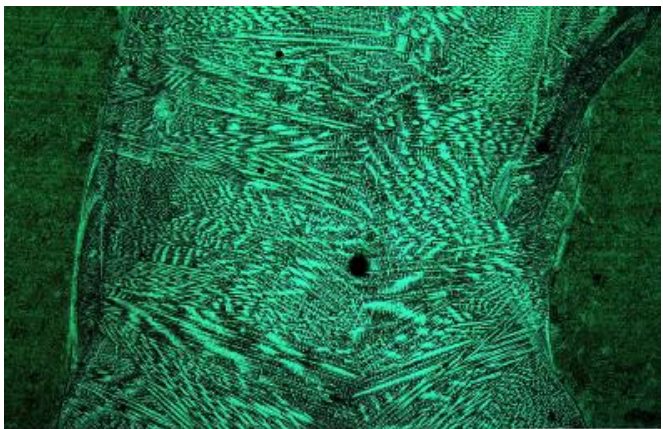

(c) $500 \mu \mathrm{m} \quad(\mathrm{d})$

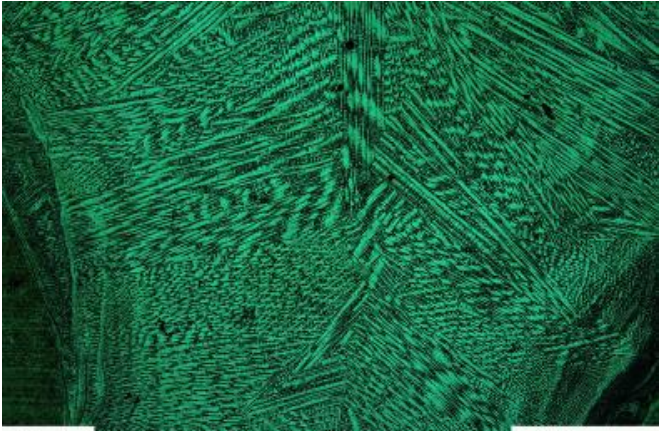

(b)

$500 \mu \mathrm{m}$

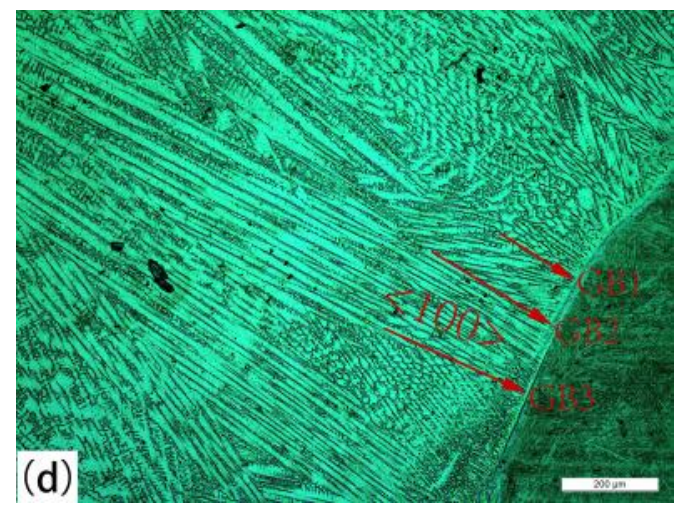

Fig.6 Solidification structures of the welded joints for ALHW; (a) arc zone, (b) transition zone and (c) laser zone, (d) columnar dendrite in transition zone at high magnification. 

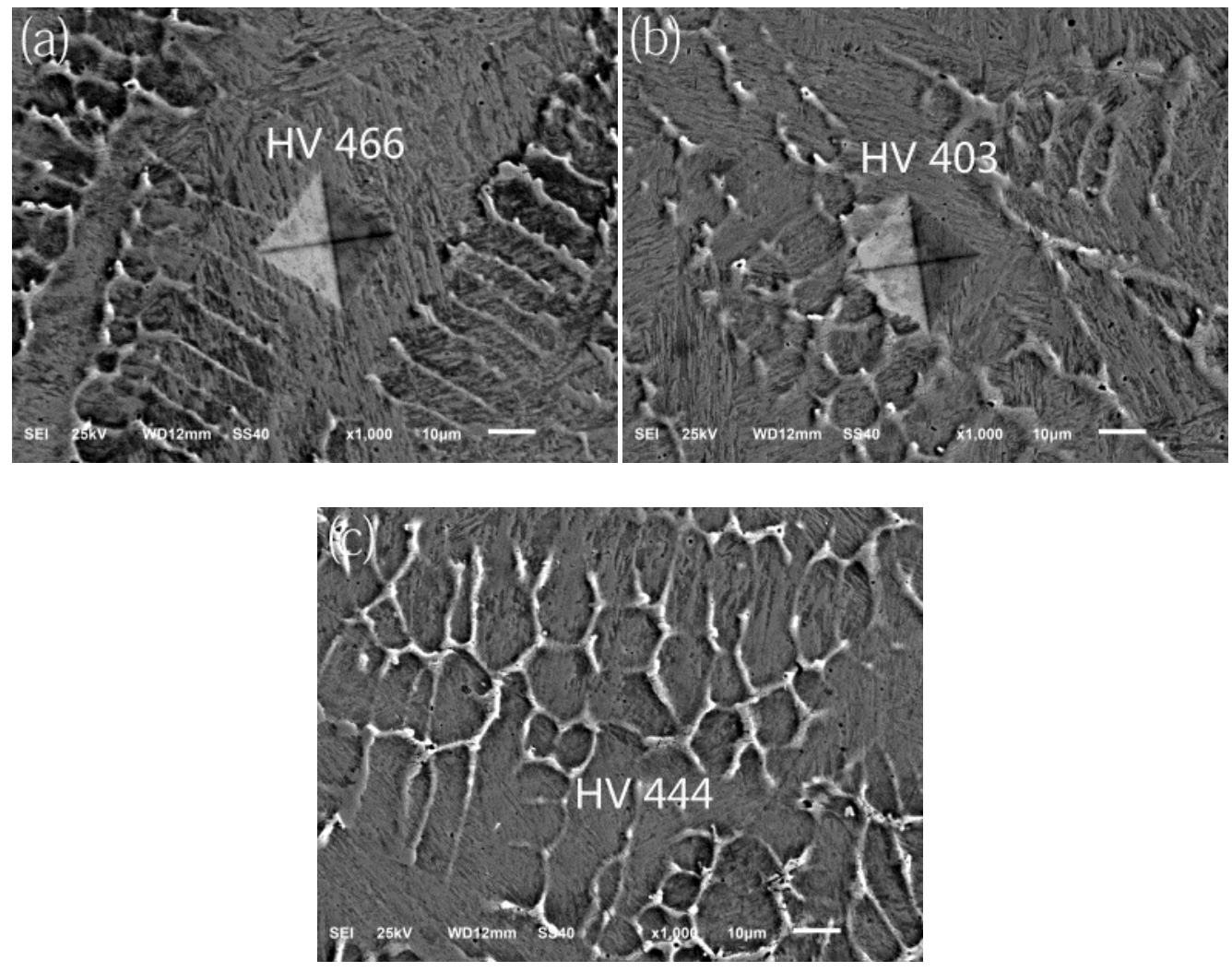

Fig.7 Microstructure of the fusion zone of ALHW. (a) arc zone, (b) transition zone and (c) laser zone 

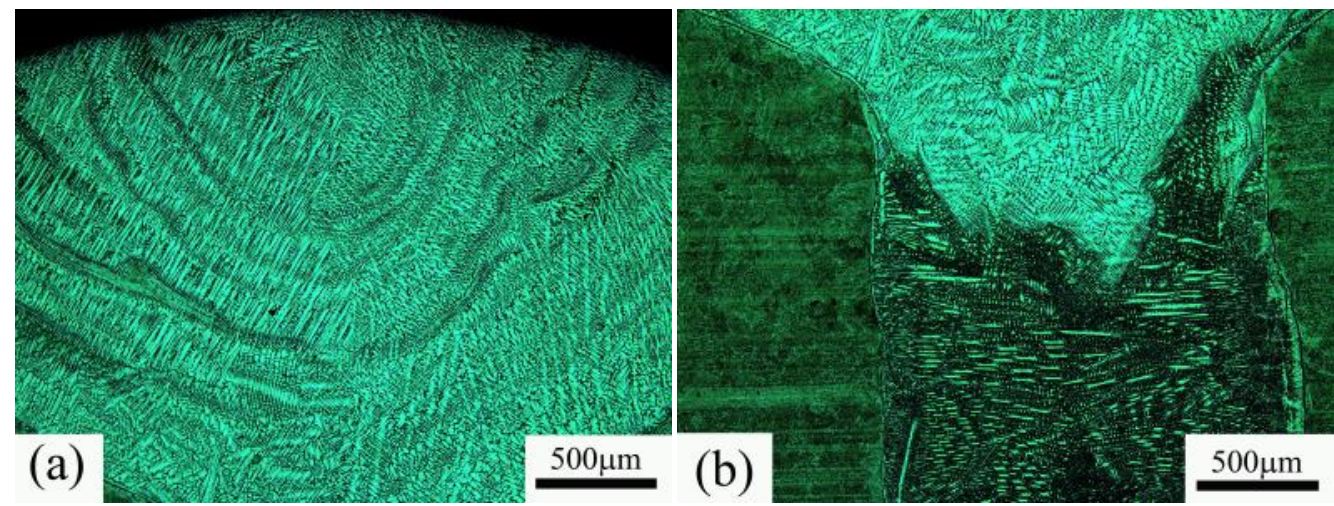

列

(b)

$500 \mu \mathrm{m}$

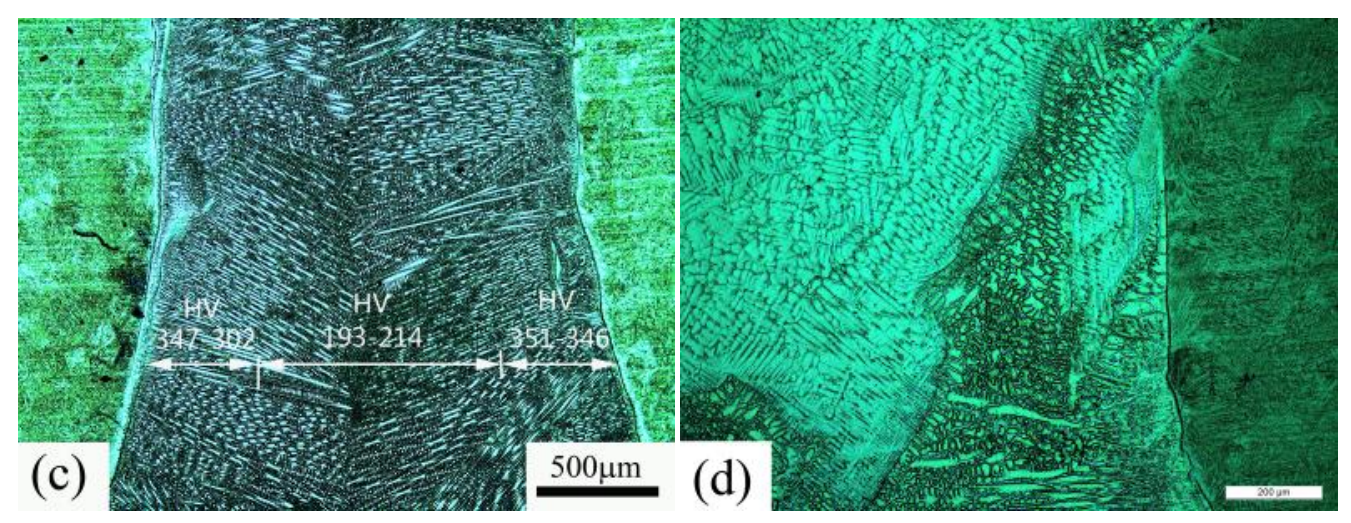

Fig.8 Solidification structures of the welded joints for LAHW; (a) arc zone, (b) transition zone and (c) laser zone, (d) short and coarse dendrite in transition zone at high magnification. 

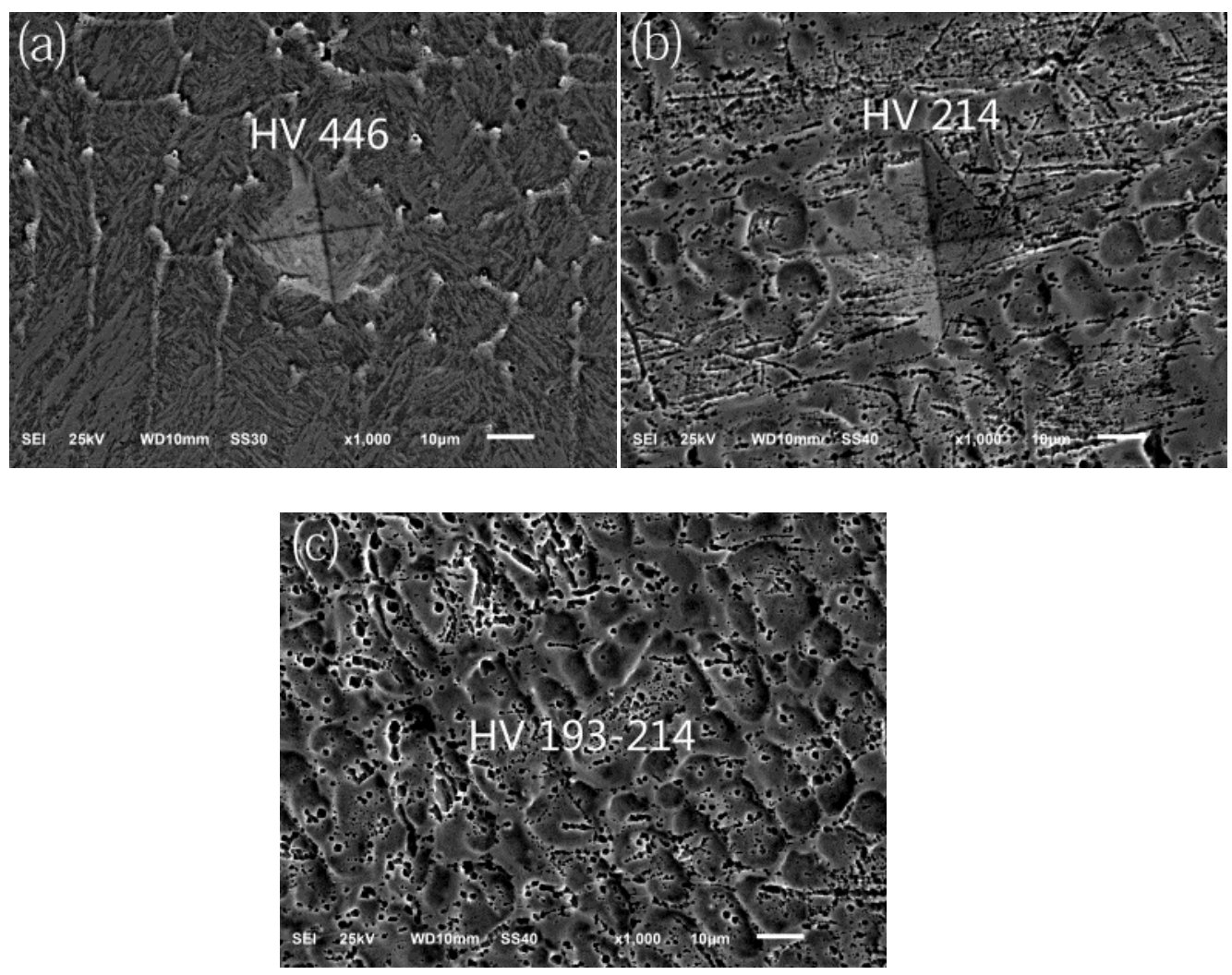

Fig.9 Microstructure of the welded joints for LAHW. (a) arc zone, (b) transition zone and (c) laser zone
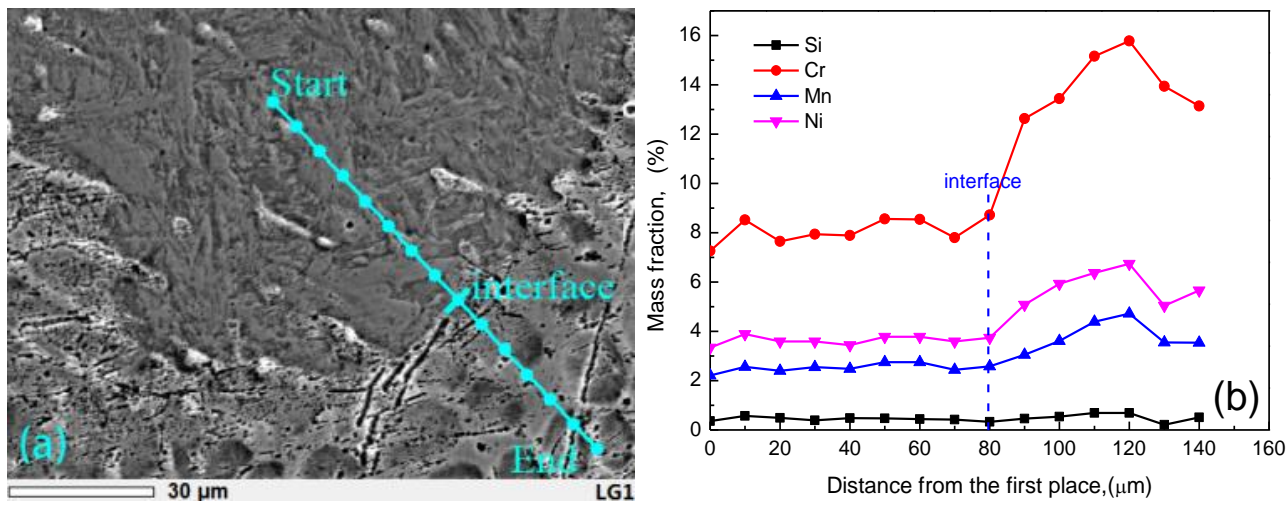

Fig. 10 Chemical composition of LAHW weld. (a) Micrograph with EDS measurement path; (b) Elements distribution curves from EDS measurement. 


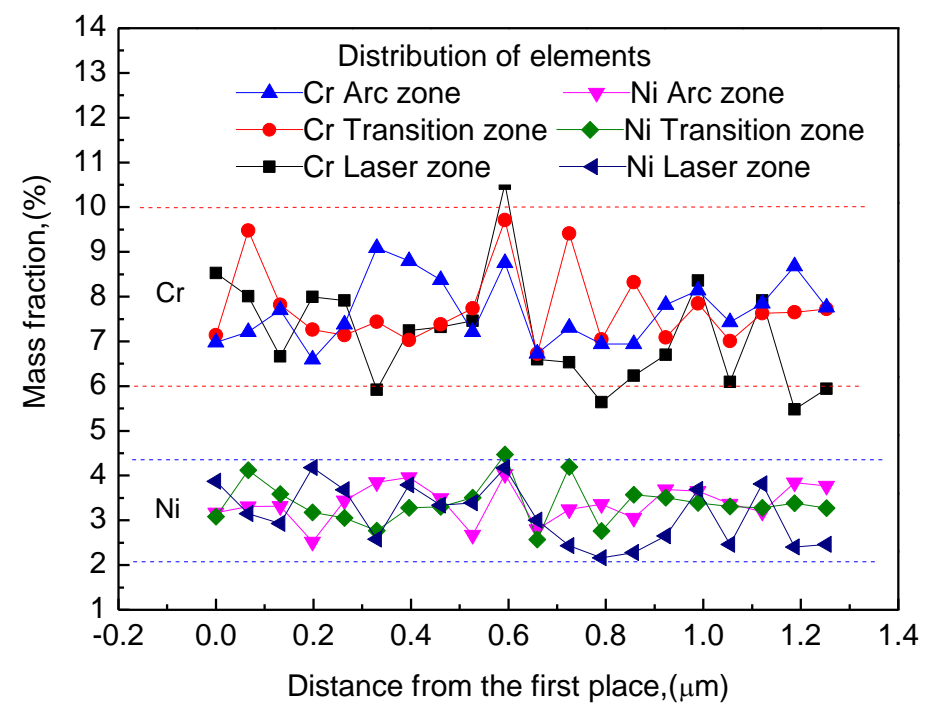

Fig.11 Distribution of Ni and Cr elements in the ALHW welded seam.

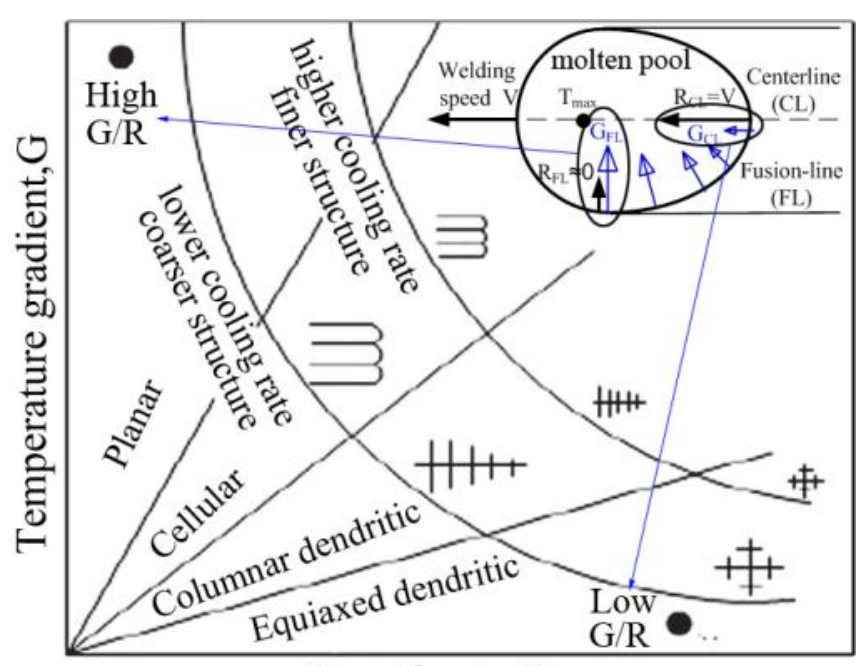

Growth rate, $\mathrm{R}$

Fig.12 Schematic view illustrating the effects of temperature gradient $\mathrm{G}$ and growth rate $\mathrm{R}$ on the morphology of solidification microstructure ${ }^{[14]}$. 

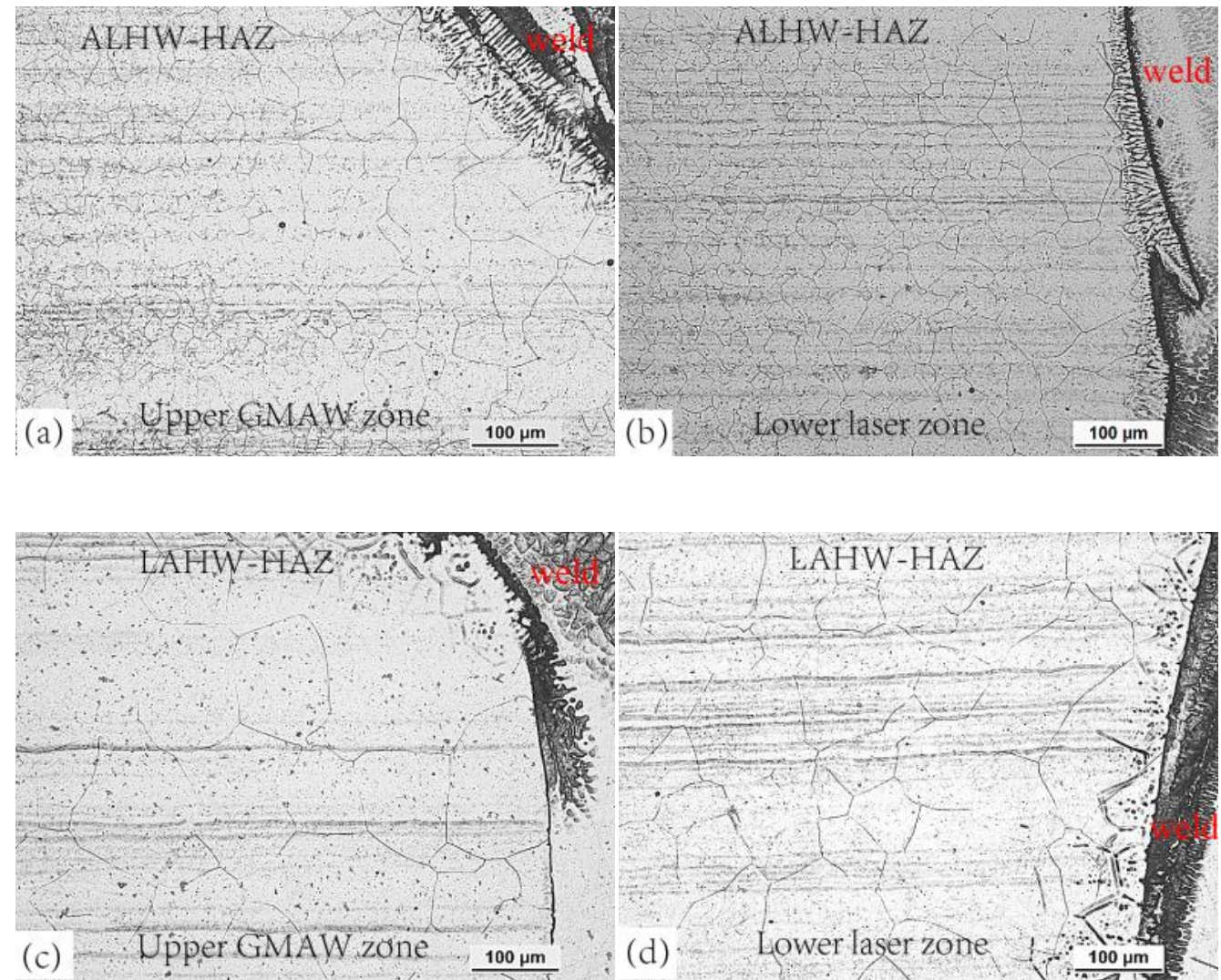

Fig.13 The grain size of HAZ for (a) ALHW and (b) LAHW

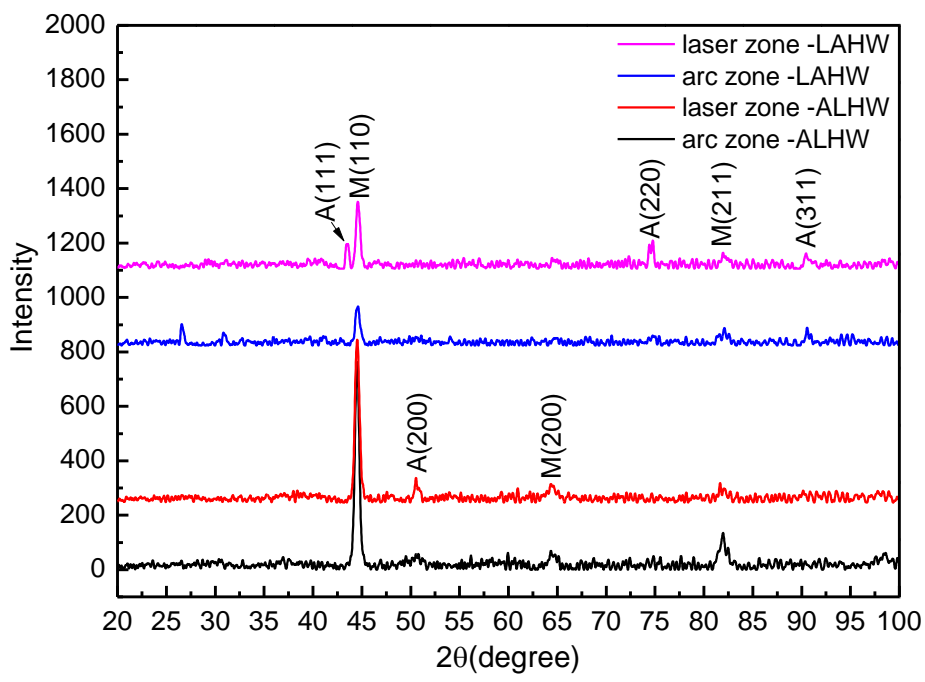

Fig.14 X-ray diffraction (XRD) analysis result of the weld metal. 

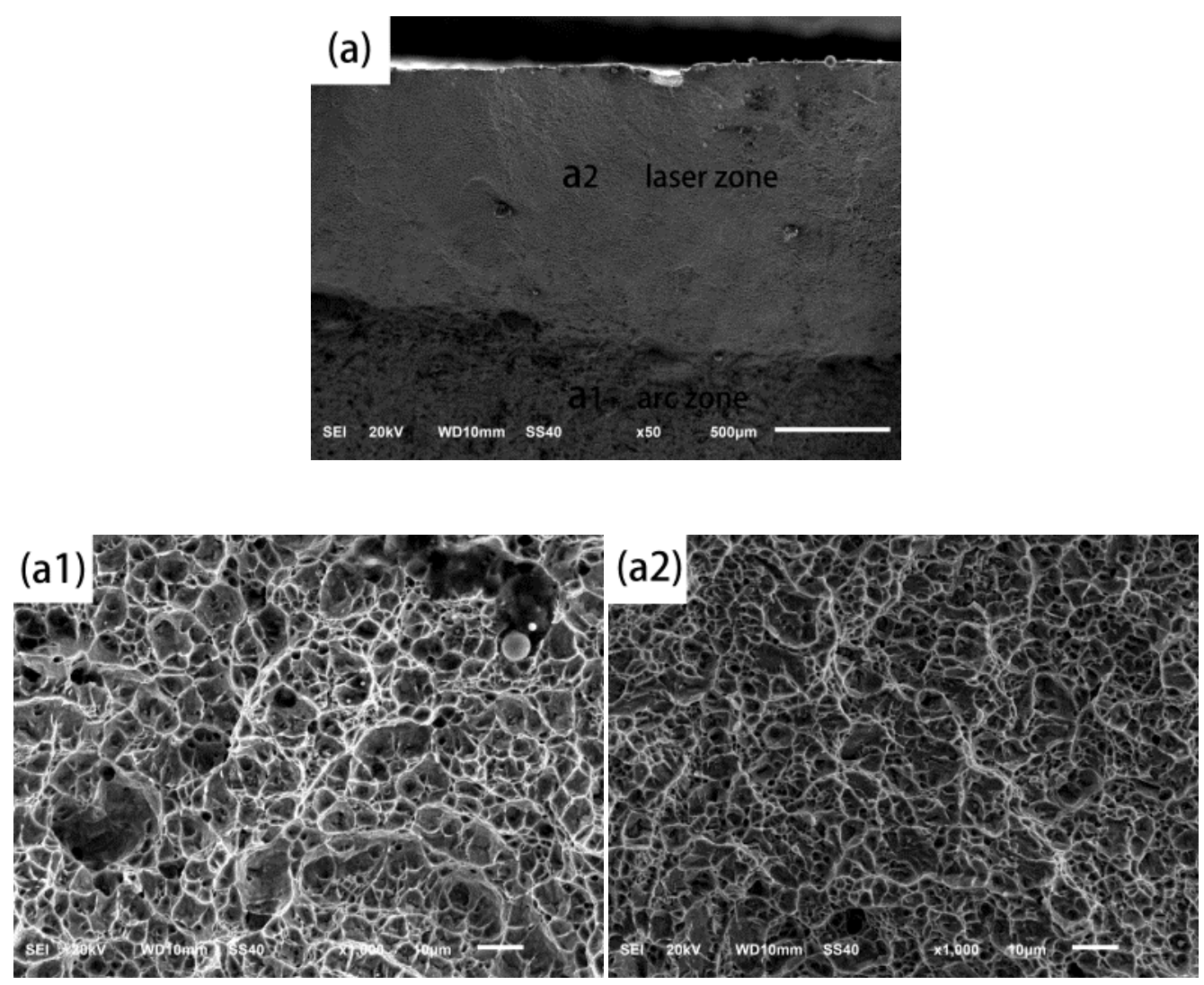

Fig.15 Fracture surface of the welded joints for ALHW
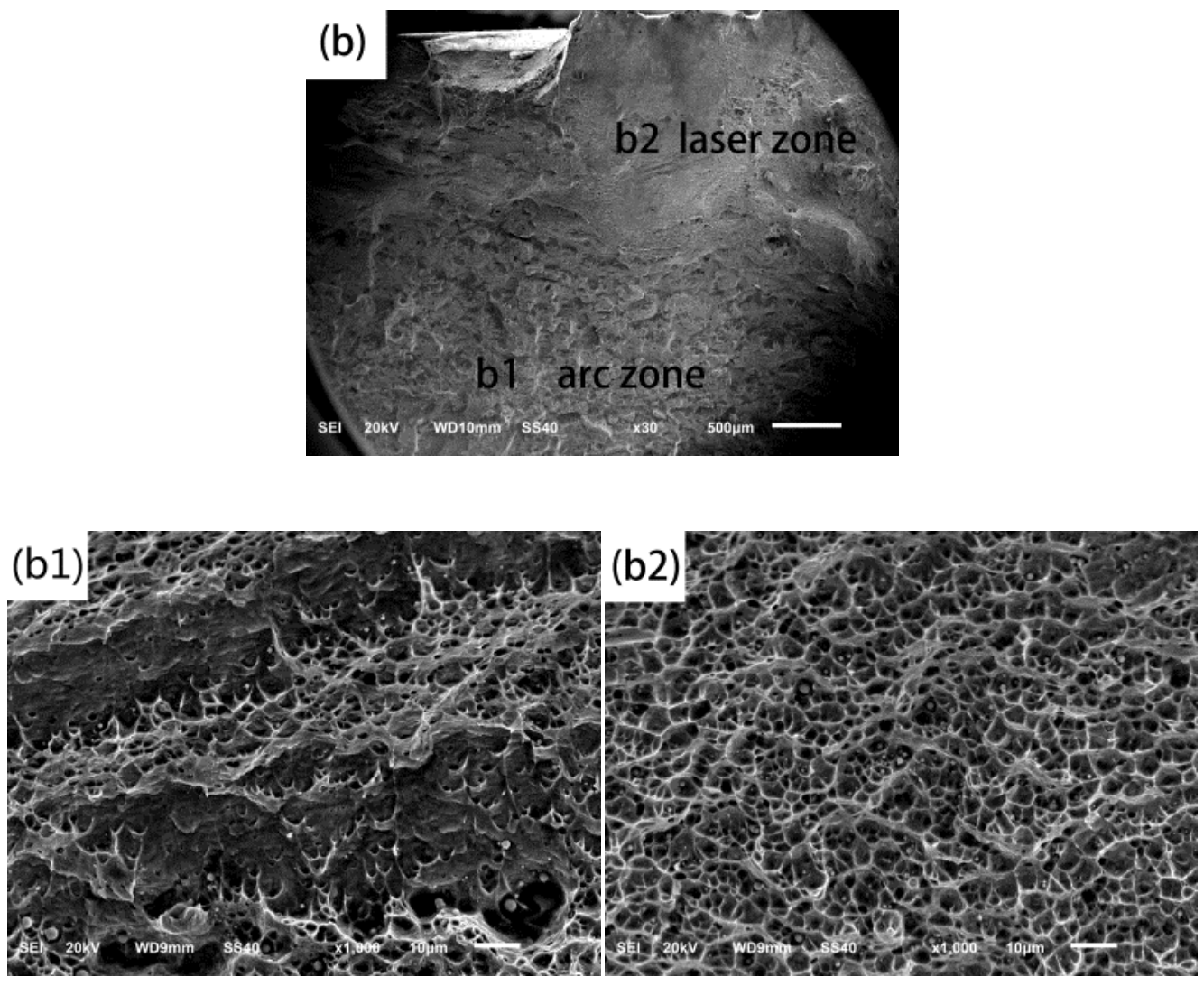
Fig.16 Fracture surface of the welded joints for LAHW

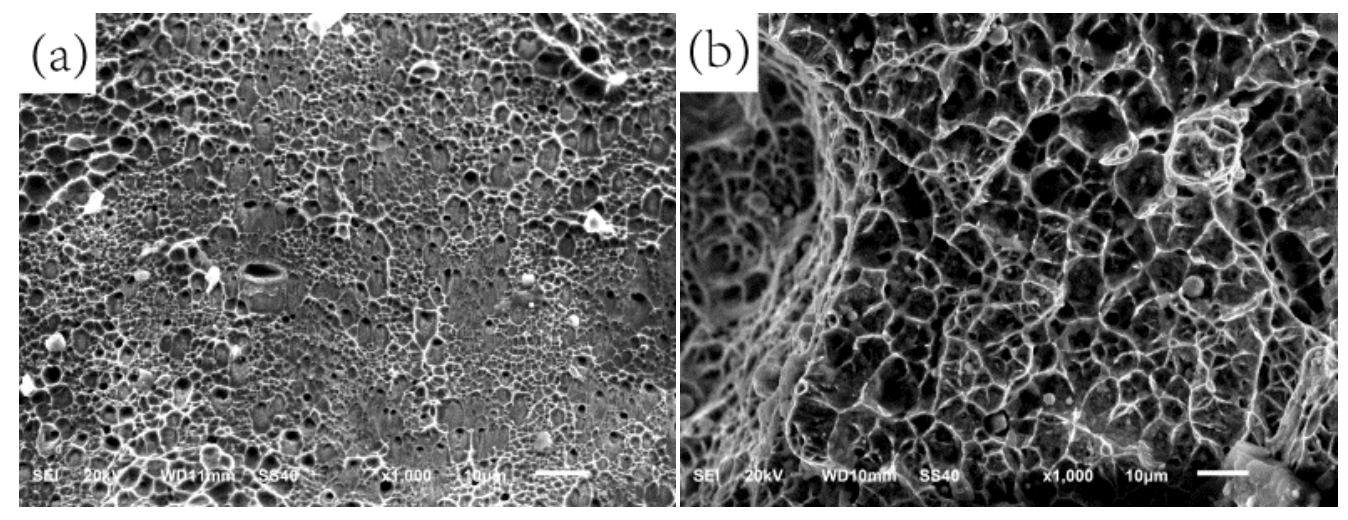

Fig.17 Fracture surface of Charpy V tested specimen: (a) ALHW, (b) LAHW 